\title{
Подавление нелинейного шума в высокоскоростных линиях связи с компенсацией дисперсии
}

\author{
Е.Г. Шапиро, Д.А. Шапиро* \\ ${ }^{1}$ Институт автоматики и электрометрии СО РАН, Новосибирск \\ ${ }^{2}$ Новосибирский государственный университет, Новосибирск \\ *E-mail: shapiro@iae.nsk.su
}

DOI:10.31868/RFL2018.214-215

Волоконная оптика развивается уже несколько десятилетий. Для увеличения пропускной способности линий связи используется многоканальная передача информации, высокая скорость в отдельном канале, форматы кодирования высокого порядка и др. Одними из основных факторов искажения сигнала являются шумы усиления и нелинейные эффекты, сопровождающие распространение сигнала.

Рассмотрены два способа подавления керровской нелинейности в высокоскоростной линии связи с компенсацией дисперсии, передающей сигнал с четырьмя уровнями амплитудной модуляции: большое положительное чирпирование входных импульсов и большая отрицательная дисперсия. Показано, что одновременное использование этих способов существенно улучшает качество сигнала.

Выполнен численный расчет распространения сигнала в рамках нелинейного уравнения Шредингера для одного канала. Линия связи состояла из 20 секций вида

$$
S M F(100 \mathrm{KM})+E D F A+D C F+E D F A .
$$

Эрбиевые усилители полностью компенсировали затухание сигнала на участке волокна. Длина участка DCF выбиралась такой, чтобы обеспечить заданный уровень средней дисперсии $\langle D\rangle$. Входной сигнал задавался формулой

$$
S(t)=\sum_{n} a_{n}(t-n T), \quad a_{n}(\tau)=B_{n} \exp \left(-\frac{\tau^{2}-i c_{n} \tau^{2}}{2 T_{0}^{2}}\right),
$$

где $B_{n}=B \xi_{n}, \xi_{n}$ - значение случайной величины, которое с вероятностью $1 / 4$ равно одному числу из множества $\{1,2,3,4\}$. На приемном устройстве мощность сигнала усреднялась по битовому интервалу длительностью 25 пс. При $\xi_{\mathrm{n}}=1$, мощность импульса составляла 1.3 мВт, ширина — 6.7 пс. Параметр положительного чирпа $c_{n}$ выбирался для каждого значения мощности импульса отдельно. Возможные значения параметра чирпа можно рассматривать как вектор $c=\left(c_{1}, c_{2}, c_{3}, c_{4}\right)$, здесь $c_{1}$ соответствует импульсам с минимальной мощностью, а $c_{4}-$ с максимальной.

На рисунках приведены гистограммы битовых значений на приемнике. На рис. 1(a) изображен график для нулевой дисперсии и нулевого начального чирпа: $\langle D\rangle=0, c=(0,0,0,0)$. На рис. 1(b) приведен график для нулевой дисперсии и ненулевых параметров начального чирпа: $\langle D\rangle=0, \mathrm{c}=(15,13,19,7)$. На рис. 1(c) приведен график для ненулевой дисперсии и начального чирпа: $\langle D\rangle=-1.2$ пс/(нм км $), c=(15,13,19,7)$. 
При большой отрицательной дисперсии линии связи усиление сигнала и компенсация дисперсии происходят в разных точках [1]. Поэтому усиливаются импульсы, которые шире начальных, а форма восстанавливается у импульсов с меньшей мощностью в силу затухания. Это уменьшает керровскую нелинейность. Положительное чирпирование вызывает быстрое уширение импульсов [2], что также уменьшает нелинейное взаимодействие сигнала.

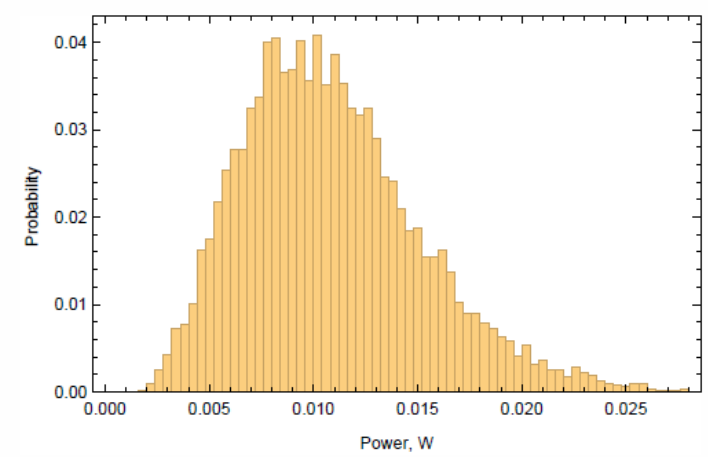

(a)

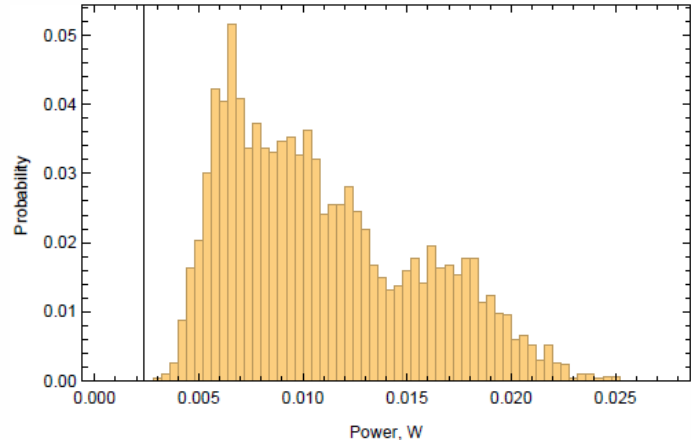

(b)

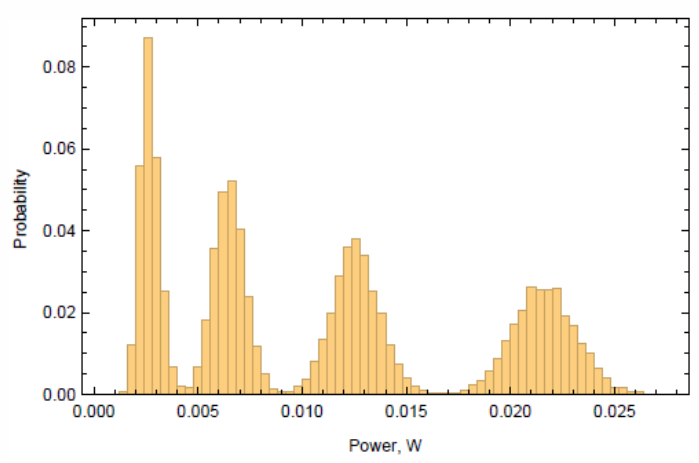

(c)

Рис. 1. Гистограммы распределений по амплитуде сигнала.

\section{Литература}

[1] E.G. Shapiro, M.P. Fedoruk et al, Opt. Comm. 250(1-3) 202-206 (2005).

[2] G. P. Agrawal, Nonlinear fiber optics, Amsterdam: Elsevier, 2007, 529 pp. 